УДК 38.04.02

ГРОМОВ Вадим Владимирович - слушатель Академии управления Министерства внутренних дел России (125171, Россия, г. Москва, улииа Зои и Александра Космодемьянских, 8; Grom-Vadim@таil.ru)

\title{
К ВОПРОСУ О ПОНЯТИИ И ВИДАХ ТАКТИКИ ОХРАНЫ ОБЩЕСТВЕННОГО ПОРЯДКА
}

Аннотация. В статье раскрываются понятия тактики охраны общественного порядка, ее виды и действия руководителей органов внутренних дел при охране общественного порядка и обеспечении общественной безопасности в современных условиях.

Ключевые слова: организация, управление, общественный порядок, тактика охраны правопорядка, общественная безопасность

И значально своим лексическим значением понятие «тактика» было обязано военному искусству [Ракушин 2012: 12], хотя спустя несколько тысячелетий она перестала является некой частностью упомянутой сферы общественных отношений, впрочем, так же, как и любой иной области практической деятельности человека. Сегодня, являясь одним из объективных общественных явлений, тактика пронизывает практически все обстоятельства жизни государства и общества.

Применительно к деятельности органов внутренних дел (ОВД) тактика всесторонне исследовалась учеными в таких сферах, как криминалистика, оперативно-разыскная деятельность, несение наружной службы патрульно-постовыми нарядами, режимная деятельность специальных подразделений полиции и т.д. [Белкин 1993: 36; Баев 1977: 43].

Важно отметить, что в каждой сфере своего практического применения исследуемое понятие приобретает собственные особенности и индивидуальный смысл, оставаясь при этом в целом не чем иным как совокупностью «средств, приемов и способов для достижения намеченной цели» [Селиверстов 1999: 364].

В некоторых научно-практических источниках тактику называют «столкновением интересов, борьбой, соревнованием, активным стремлением к цели» [Управление деятельностью... 2000: 12]. Наличие определенного противоборства сторон либо их соревновательности в стремлении достичь поставленной цели, несомненно, можно отнести ко второму объективному и весьма существенному признаку тактики. Например, действующая военная доктрина Российской Федерации, представляющая собой систему официальных взглядов на подготовку к вооруженной защите государства, раскрывает первостепенное значение борьбы с международным терроризмом, пиратством, средствами высокоточного оружия ${ }^{1}$.

Опираясь на прикладное значение тактики в осуществлении борьбы с какими-либо деструктивными процессами в обществе либо в организации противодействия самым различным асоциальным проявлениям, можно выявить и обосновать еще одну особенность (признак) исследуемого понятия, а и именно то, что в указанных масштабах «тактику нельзя рассматривать вне стратегии». Особыми «стратегическими национальными приоритетами» принято называть самые важные и ответственные направления обеспечения национальной

${ }^{1}$ Военная доктрина Российской Федерации. Утв. Президентом РФ 25.12.2014 № Пр-2976. Российская газета. № 298. 30.12.2014. Стр. 11. 
безопасности в нашем государстве ${ }^{1}$. Именно поэтому тактика деятельности любого субъекта обеспечения безопасности является своеобразной подсистемой в системе охраны общественного порядка (ООП) и связанной с ней охраны общественной безопасности (ООБ) как тактика обеспечения правопорядка, розыск лиц (оперативно-разыскная тактика), экспертно-криминалистическая деятельность (криминалистическая тактика), выявление и раскрытие преступлений (следственная тактика). В каждом из перечисленных случаев применяется особая тактика пресечения и (или) недопущения противоправных проявлений, что по своей сути означает наличие отдельных, но очень тесно взаимосвязанных и взаимообусловленных элементов единого процесса обеспечения правопорядка в современном демократическом обществе.

В результате общее понимание тактики сводится к тому, что она представляет собой неотъемлемую часть вышеуказанного процесса. При этом такого рода деятельность (в рамках этого процесса) осуществляется на фоне динамично развивающихся общественных правоотношений. Помимо такого динамичного характера, тактика, связанная с ООП и ООБ, носит отчетливо выраженный исполнительный, подчиненный и непосредственный характер.

Динамичность тактики проявляется в «непрерывном выборе способа поведения в зависимости от условий, факторов окружающей действительности». Следующие качества тактики весьма наглядно проявляются ввиду зачастую нестабильной оперативной обстановки, на фоне изменения которой требуется принятие взвешенных решений. Причем такие решения должны быть подчинены не только здравому смыслу и профессиональной интуиции руководителя, но и определенной государством стратегии обеспечения безопасности участников современных общественных правоотношений. Ну и, наконец, «непосредственность тактики» может быть охарактеризована как исключительная необходимость решать непосредственно возникающие оперативно-служебные задачи.

Понимание тактики как совокупности (системы) способов действий характеризует только одну ее сторону, которую можно определить как статичную по отношению к другой, более динамичной стороне тактики. Динамика тактики проявляется в выборе из множества способов (приемов, линий поведения, методов, форм) наилучшего варианта действий в конкретной ситуации (обстановке) и его реализации.

В таком контексте тактику следует рассматривать как определяемый логикой, интуицией и практическим опытом «процесс мыслительных операций и практических действий» руководителя, который осуществляется на основе анализа информации и необходим для принятия (выбора) наиболее приемлемого тактического решения с целью его последующей результативной реализации.

Реализовать такой мыслительный процесс на практике весьма сложно в силу самых разнообразных обстоятельств, требующих дополнительного пояснения. В основном это совокупность элементов, различных условий и факторов, оказывающих основное влияние на деятельность ОВД, получившая название оперативной обстановки [Москалев 2015: 19]. Учитывая самые разнообразные факторы внутренней и внешней среды своего формирования, оперативная обстановка (ее состояние) в определенное время должна являться предметом первоочередного мыслительного процесса руководителя территориального

1 Указ Президента РФ от 31.12.2015 № 683 «О Стратегии национальной безопасности РФ». Собрание законодательства РФ. 2016. № 1 (часть II). Ст. 212. 
органа внутренних дел (ТОВД), уполномоченного принимать соответствующие тактические решения.

Исследуя наиболее важные факторы внешней среды сложившейся оперативной обстановки, руководитель ТОВД должен анализировать всю гамму социально-экономических, общественно-политических и иных процессов, способствующих возникновению противоправных проявлений в той или иной сфере общественных отношений. Выбор неверной тактики действий имеющихся сил и средств может не просто обернуться отсутствием статистически результативной работы, но и спровоцировать совершенно непредсказуемые последствия, которые, в свою очередь, нанесут существенный урон имиджу ОВД и правоохранительной системы в целом.

Навыки выбора (определения) наиболее оптимальных тактических форм деятельности в ООП начальнику ТОВД чаще всего приходится принимать, «пропуская через свое сознание» огромный поток информации, большая часть которой не является важной, а та, которая действительно представляет тактический интерес, как правило, может быть фрагментарной или отсутствовать вообще. Она также может характеризоваться большим количеством умышленно или случайно допущенных искажений. Между тем приемлемое и грамотное тактическое решение порой требует не только быстрого принятия, но и незамедлительного практического воплощения подчиненными сотрудниками, задействованными в ООП.

Именно поэтому тактика должна рассматриваться как некая система научных знаний, положений, принципов, а также соответствующих правоустановлений по планированию, организации, осуществлению ООП и ООБ.

Анализируя деятельность ОВД по ООП и ООБ, Л.Л. Попов и Б.А. Киселев дифференцировали и с научной точки зрения обосновали следующие «тактические принципы: активность; сосредоточение усилий в соответствующее время, в решающем месте; согласованное использование сил и средств; комплексное использование и тесное взаимодействие сил и средств; сочетание действий нарядов ППС с оперативно-разыскными мерами и режимными мероприятиями; внезапное (неожиданное) для правонарушителей применение сил и средств по месту, времени, а также по формам и методам действий; своевременный маневр силами и средствами; использование резервов; профилактическую направленность охраны общественного порядка; непрерывность и гибкость; наличие резерва сил и средств» [Попов, Киселев 1995: 70].

Следует подчеркнуть, что научно обоснованные тактические принципы нельзя анализировать и применять практически обособленно друг от друга. Это важно в силу их неразрывного диалектического единства. Каждый сформулированный принцип является неотъемлемыми сегментом системы тактических форм и методов ООП и ООБ. Разумеется, процесс обеспечения правопорядка не может замыкаться только на исключительно тактических принципах. Наряду с таковыми он (процесс ООП и ООБ) зиждится на целом комплексе общеправовых представлений о законности, соблюдении прав и иных интересов участников соответствующих правоотношений.

Таким образом, характеризуя особенности тактики ООП и ООБ, следует отметить, что это административно-правовое явление, рассматриваемое в своей статике и динамике, представляет собой: а) важный атрибут административной деятельности ОВД; б) мощнейшее средство административно-правового, психологического, физического и иного воздействия на участников общественных отношений, возникающих при осуществлении ООП и ООБ; в) неотъемлемый элемент системы правовых, организационных и технических мер, принимаемых в процессе ООП и ООБ. 
Еще одной важной особенностью тактики ООП и ООБ является то, что она может использоваться как индивидуальными, так и коллективными субъектами административно-правового воздействия на участников правоотношений, допускающих (намеренных допустить) нарушение установленных правовых запретов, предписаний или дозволений.

При этом индивидуальный вид тактики ООП и ООБ - это реализация выбранных уполномоченным должностным лицом ТОВД (организующим непосредственную ООП) наиболее целесообразных средств и способов (приемов) действий, направленных на предупреждение и пресечение противоправных деяний или их возможных последствий. Индивидуальная тактика ООП и ООБ в общественных местах реализуется не только на основе теоретических знаний и практического опыта. Важнейшее значение в тактике ООП и ООБ имеет административное усмотрение (производная интуиции).

Классифицируя разновидности административного усмотрения, А.Ф. Самороковский и В.А. Цупко вычленили «участок (сферу) административного усмотрения, который “отвечает” за принятие такого решения в совершении тактических действий» [Самороковский, Цупко 2007: 39]. Называя административное усмотрение производной интуиции, следует указать на их существенное различие, как если бы речь шла о так называемом свободном интуитивном усмотрении, не исключающем в весьма редких случаях и социальные формы ООП и ООБ. Административное же усмотрение в тактике ООП и ООБ всегда носит правовой характер, а потому и является правовым усмотрением.

Коллективный вид тактики ООП и ООБ проявляется преимущественно в государственном масштабе. Он представляет собой подчиненный стратегическим правоохранительным целям правомерный, взаимообусловленный состоянием оперативной обстановки тактический режим административной деятельности по осуществлению наиболее целесообразных видов, форм и методов, приемов и способов непосредственной ООП и ООБ при оптимальном использовании возможностей сил и средств ПП ООП, других правоохранительных органов, должностных лиц государственной и муниципальной власти, граждан, а также их общественных объединений правоохранительной направленности.

Подробно исследуя виды и понятие тактики ООП, никак нельзя обойти вниманием ее соотношение с еще одним очень важным понятием - таким как «организация». С одной стороны, тактика, несомненно, является составной частью организации. С другой - тактика сама включает в себя организацию как обязательную управленческую функцию в ходе управления процессом ООП и ООБ. Очевидно, необходимо более четко разграничить два этих важных понятия.

Представляется, что «тактика» и «организация» являются двумя взаимообусловленными по значению понятиями. Доказательством тому служит очевидное обстоятельство, связанное с необходимостью управления комплексными силами и средствами правопорядка, которые задействованы в реализации тактических замыслов должностных лиц в ходе ООП.

Из этого следует, что тактика, представляющая собой совокупность управленческих действий, невозможна без организационно-управленческого внутреннего содержания. В свою очередь, организация обретает первооснову тактики ООП. Как уже было отмечено, организация как бы предшествует тактике в силу того, что именно с нее и начинает реализовываться комплекс последовательных управленческих функций ООП и ООБ.

Таким образом, исследование понятия и видов тактики ООП позволяет сделать следующие выводы. 
1. Тактика ООП представляет собой определяемый логикой, административно-правовым усмотрением и практическим интуитивным опытом процесс мыслительных операций и практических действий уполномоченного руководителя ТОВД по воплощению наиболее приемлемой совокупности форм и методов, способов и приемов ООП. Указанный мыслительный процесс осуществляется на основе анализа оперативной обстановки и необходим для принятия (выбора) наиболее оптимального тактического решения, направленного на успешное и результативное ОП в ОМ.

2. К элементам тактики ООП относятся формы и методы, способы и приемы деятельности нарядов, задействованных в ООП.

3. Сущность тактики ООП выражается в определении тех форм и методов, способов и приемов деятельности нарядов, задействованных в ООП, которые более всего соответствуют конкретной оперативной обстановке и направлены на успешное выполнение поставленных задач.

4. Особенности тактики ООП проявляются в том, что это административноправовое явление представляет собой:

а) атрибут административной деятельности ОВД;

б) средство административно-правового, психологического, физического и иного воздействия на участников общественных отношений, возникающих при осуществлении ООП и ООБ;

в) элемент системы правовых, организационных и технических мер, принимаемых в процессе ООП и ООБ.

5. Тактика ООП может использоваться как индивидуальными, так и коллективными субъектами административно-правового воздействия на участников правоотношений, допускающих (намеренных допустить) нарушение установленных правовых запретов, предписаний или дозволений.

6. «Организация ООП» и «тактика ООП» являются двумя взаимообусловленными понятиями.

Тактика ООП представляет собой совокупность управленческих действий и поэтому невозможна без организационно-управленческого внутреннего содержания. Тактика является составной частью этого содержания, его динамичной исполнительской стороной, выражающейся в применении различных приемов и способов обеспечения правопорядка.

Организация ООП обретает первооснову тактики и предшествует ей в силу того, что именно с организации начинает реализовываться комплекс последовательных управленческих функций ООП и ООБ.

\section{Список литературы}

Баев О.Я. 1977. Криминалистическая тактика и уголовно-процессуальный закон. Воронеж: Изд-во Воронежского университета. 116 с.

Белкин Р.С. 1993. Очерки криминалистической тактики. Волгоград: Изд-во ВСШ МВД РФ. 200 с.

Москалев М.А. 2015. Аналитическая деятельность подразделений территориальных органов МВД России на региональном уровне. М.: Спутник. 79 с.

Попов Л.Л., Киселев Б.А. 1995. Обязанности и права нарядов милиции. М.: Академия МВД России. 72 с.

Ракушин П.А. 2012. Тактические основы охраны общественного порядка органами внутренних дел: дис. ... к.ю.н. М.: Академия МВД России.180 с.

Самороковский А.Ф., Цупко В.А. 2007. Административное усмотрение как принцип тактики охраны общественного порядка: отчет о НИР. М.: ВИ МВД России. 
Селиверстов С.А. 1999. Оперативно-боевая подготовка для спеиподразделений милиции МВД России: учебно-методическое пособие. М.: Изд-во МВД. 736 с.

Управление деятельностью служб общественной безопасности (под ред. Ю.Н. Ольховникова, Ф.П. Колонтаевского). 2000. М.: Академия управления МВД. 265 c.

GROMOV Vadim Vladimirovich, student of the Academy of Management of the Interior Ministry of Russia (8 Zoe and Alexander Kosmodemyanskih St, Moscow, Russia, 125171; Grom-Vadim@mail.ru.ru)

\section{TO THE QUESTION OF THE CONCEPT AND TYPES OF TACTICS OF PUBLIC PEACE}

Abstract. The article describes the concepts of tactics for the protection of public peace, its types and actions of the heads of internal affairs bodies in the protection of public peace and ensuring public safety in modern conditions.

Keywords: organization, management, public peace, law enforcement tactics, public security 